\title{
A Multi-agent Intelligent Decision Making Support System for Home Energy Management in Smart Grid: A Fuzzy TOPSIS Approach
}

Omid Ameri Sianaki ${ }^{1,2}$ and Mohammad A.S. Masoum ${ }^{2}$

1) School of Information Systems, Curtin University, Perth, WA, Australia, Omid.amerisianaki@ postgrad.curtin.edu.au

2) Department of Electrical and Computer Engineering, Curtin University, Curtin University, Perth, WA, Australia, m.masoum@curtin.edu.au

\begin{abstract}
In the context of intelligent home energy management in smart grid, the occupants' consumption behavior has a direct effect on the demand and supply of the electrical energy market. Correspondingly, the policies of the utility providers affect consumption behavior so techniques and tools are required to analyse the occupants' preferences, habits and lifestyles in order to support and facilitate their decision-making regarding the curtailing of their energy consumption and costs. The uncertainty about householders' preferences increases the uncertainty of appliance prioritization and makes it difficult to determine the consistency of preferences in terms of energy consumption. In this complex system, the preferences and judgments of householders are represented by linguistic and vague patterns. This paper proposes a much better representation of this linguistics that can be developed and refined by using the evaluation methods of fuzzy set theory. The proposed approach will apply the fuzzy Technique for Order Preference by Similarity to Ideal Solution (fuzzy TOPSIS) for achieving preferences. Based on our detailed literature review of the multi-agent system approach in this field, it is expected that the proposal model will offer a robust tool for communication and decision-making between occupant agents and dynamic environmental variables. It is shown that the proposed fuzzy TOPSIS approach will enable and assist householders to maximize their participation in demand response programs.
\end{abstract}

Keywords: Multi-agent systems, demand response, dynamic real-time pricing, fuzzy TOPSIS, intelligent decision support system, home energy management, smart grid, smart home, scheduling model

\section{INTRODUCTION}

Much of the research conducted on home energy management affirms that the study and analysis of the characteristics of householders' consumption behavior such as preferences, habits and lifestyles are crucial for the forecasting of energy demand in the total electricity supply chain management.

In order to gather all information about the behavior of suppliers and consumers, the smart electrical grid utilizes the ubiquitous communication and automated network infrastructures and services. As a result, the future smart homes of smart grid are proactive with the ability to negotiate, collaborate and interact with their external environment. Furthermore, these smart homes will also be equipped with robust facilities required to utilize renewable resources such as solar and wind energy. Smart homes use a combination of centralized and decentralized renewable and non-renewable electricity resources as distributed generation for improving the efficiency, reliability and sustainability of the smart grid. Therefore, one of the main issues of the future grid is maintaining a balance between the demand and 
supply of electricity in order to prevent load instabilities in the network. Consequently, a key factor that must be considered in order to resolve this issue is how to extend the smart grid so that it can effectively interact and communicate with consumers; this collaboration cannot be achieved unless the characteristics of end-users' consumption behavior are discovered.

For this reason, one of the main goals of the smart grid is to obtain the end-users' collaboration in order to consume electricity more efficiently [1]. Demand response (DR) refers to mechanisms used to encourage or to induce consumers to reduce or to shift their demand in order to decrease aggregate demand at particular times. Dynamic DR refers to the optimization of the load profile of householders in terms of the grid resources in order to prevent the system from overloading and to curtail the cost of electricity [2].

To date, significant research has been conducted on the integration of customer-demand-side management into smart grids for improving the system load profile and reducing peak demand. To achieve this, many countries are developing technologies such as smart metering and smart appliances. For instance, Italy and Sweden are close to one hundred percent deployment of smart meters for consumers in addition to having smart household appliances such as dishwashers, air-conditioning units, clothes dryers, washing machines and plug-in electric vehicles (PEVs) that can "talk" to the grid and "decide" how best to operate and automatically schedule their activities at strategic times based on the available generation [3].

End-user behaviors are defined as the actions and decisions taken by occupants of buildings that have impacts on energy consumption. These include decisions about the use of appliances within an occupant's personal control. Consequently, the optimization of building energy and comfort becomes a complex problem requiring computational support and a real-world interface [4]. Thus, one of the most important issues for smart and energy-efficient buildings is to balance the requirements of the occupants' comfort and power consumption [5].

When consumers receive information from the grid such as price signals, they try to tail off their electricity consumption by making real-time decisions about their use of various electrical appliances [6]. The uncertainty and variation in the householders' preferences increases the uncertainty of appliance prioritization and makes it difficult to determine the consistency of preferences. In this complex system, the preferences and judgments of householders are represented by linguistic and vague patterns. A much better representation of this linguistics can be developed and refined by using the evaluation methods of fuzzy set theory. The fuzzy technique for Order Preference by Similarity to Ideal Solution (fuzzy TOPSIS) is an advanced analytical method developed from the traditional TOPSIS that can be used to determine preferences.

The importance of the consumers' role in energy demand is demonstrated in approaches about demand response, multi-agent approaches to home energy management systems (EMSs) and consumers' behaviours.

\section{A. Demand Response (DR) Programs}

Demand response (DR) refers to a mechanism by which customers participate voluntarily in reducing the peak by altering the consumption patterns of some of their appliances. The customers participating in DR may be given a monetary incentive or offered a lower tariff. The implementation of DR in smart distribution systems with multiple microgrids requires intelligent and reliable energy-management tools [4]. Responsive demand, however, refers to those changes applied by consumers to their expected load pattern in response to energy price signals for improving the economic efficiency of their energy [7]. 
One of the main goals of the smart grid is to achieve DR by increasing the end users' participation in decision-making and increasing their awareness about energy usage that will help them to efficiently manage their energy consumption. DR programs take different forms including energy efficiency and conservation programmes, static time of use pricing, critical day pricing, critical peak pricing, peak time rebates, real-time pricing (RTP), demand-side bidding and dynamic demand [8].

The underlying objective of these DR programmes is to actively engage consumers in modifying their consumption in response to pricing signals. In implementing dynamic energy pricing, the most difficult task is that of predicting people's reaction to various dynamic pricing schemes [9].

\section{B. Building Energy Management System (EMS) and Multiple Attribute Decision Making}

A home energy management (HEM) system is an integral part of a smart grid that can potentially enable demand response applications for residential customers [10]. Several papers in the literature focus on controlling appliances by means of HEM during demand response and many approaches have developed energy consumption scheduling for householders in a real-time pricing scheme [11-21]. The reviewed literature indicates that the load profile, the load shifting and scheduling, demand response and power consumption are dependent on the consumer's preferences and lifestyle. Householders prioritize their use of electrical devices according to their lifestyle, and the imposition of a demand response program leads to the possibility of a comfort level violation or a high load compensation after finishing the period of DR [10]. In this scenario, giving consideration to the householders' preferences and priorities not only increases the level of customer satisfaction and comfort, but it could also produce significant benefits for the whole energy market. For example, in real-time pricing, the price of electricity may vary hourly and is tied to the real market cost of delivering electricity [22]. So, in this situation where the decision-making for adjusting energy demand and controlling the energy cost is difficult for end-users, Multiple Attribute Decision Making (MADM) is a suitable means of addressing such problems. Of the numerous MADM methods available, the Technique for Order Preference by Similarity to Ideal Solution (TOPSIS) has received interest from researchers as a means of evaluating and selecting the energy system performance [23]. For instance, [24] developed an extended responsive load economic model based on price elasticity and customer benefit function and a prioritization of DR programs has been realized by means of the TOPSIS method; Xiaodong et al. [25] evaluated the effectiveness of the smart grid by Fuzzy TOPSIS methods.

This paper proposes a Fuzzy TOPSIS decision-making approach as a means of establishing the preferences of end-users in using groups of appliances located in different areas of the smart home. The approach considers real-time pricing scheme of demand response. A Multi-agent Intelligent Decision Making Support System (IDMSS) will be implemented to obtain the criteria for decision-making regarding home electrical energy management.

The remainder of the paper is organized as follows. Section II describes a proposed IDMSS for intelligent home energy management in smart grid. TOPSIS methodology is detailed in section III. Section IV presents detailed simulation results for a case study followed by the conclusion.

II. The Proposed Multi-agent Intelligent Decision Making Support System (IDMSS)

\section{A. Multi-agent Approaches in Efficient Home Energy Management and Smart Grid}


A multi-agent system is a combination of several agents working in collaboration to perform assigned tasks to achieve the overall goal of the system [2]. There are many publications in utilizing agents to produce solutions for specific smart grid applications. Researchers are currently developing agent-based methods to address demand response in a dynamic pricing scheme [26].

Reference [27] argued that a multi-agent system is not synonymous with an EMS. Rather, it is only one possible control method that can be applied to an EMS. Furthermore, the authors discussed that the individual characteristics of inhabitants in a smart grid can be adapted by agent-based systems and thus have the potential to raise subjective comfort. Thus, this may create a positive evaluation of the technology. That is, the systems' adaptability to occupants' needs and changes in preferences or behavior over time may be crucial for the success of the systems and their related technologies. In order to respond to the householder's requirements while integrating new sources of energy, reference [26] proposed an agent-based approach for optimizing energy consumption. In their approaches, these agents are the generators , prosumer agents and consumer agents while the goal of each agent is to maximize its profits in terms of energy unit price paid per day. Three levels of agents including grid agent, control agent and residential agent are proposed by [2]. These agents communicate with each other in order to make decisions about shifting loads to off-peak hours based on the dynamic price of electricity. In their approach, the residential agent makes the decision to change scenarios.

The application of multi-agent systems for studying comfort management of householder behavior in the context of home energy management is proposed by [4]. This approach proposed a new distributed comfort evaluation that, when compared with the traditional method of Predicted Mean Vote (PMV) index [28], reveals the need for a more robust comfort standard that allows for the input of actual occupant preferences when available.

\section{B. Proposed Multi-agent Intelligent Decision Support System for Home EMS in Smart Grid}

Householders' decision-making in regards to energy consumption is dependent on factors that influence the end-user's energy consumption behavior; hence, several surveys have been conducted to investigate these factors [18, 21, 29, 30]. For instance, Stern [31] demonstrated that the contextual domain of this behavior comprises: attributes that an individual has at birth, the immediate situation, public policy and economic variables. Kowsari et al. [29] presented a conceptual framework as a basis for formulating the household consumption behavior strategy and they proposed an integrated approach to determine the economic characteristics of a household. On the other hand, in many load scheduling and planning approaches such as those of $[16,32,33]$, the researchers have included the consumers' preferences and utility function in their optimization models. For instance, in the approaches suggested by Lampropoulos et al. [21] and Wang et al. [33], the importance of including the behavior of householders in power system planning is demonstrated but there is no methodology for obtaining and ranking these preferences.

The measurement and inclusion of these factors would be more complex when there is a conflict of preferences among several consumers in a home. This issue is demonstrated by [34] when there is "analysis talk" among household members to identify how energy savings might be made. Therefore, in the proposed approach, the aggregated fuzzy rating of criteria for more than one consumer is computed.

Following a survey of the literature $[17,21,29,31,33,35-38]$, we identified that the householders with different culture background, gender, income, education and social status who are located in different geographic locations and climate change and dealing with different energy policy, subsidies and energy 
supply, will utilize appliances in accordance with the different criteria that are presented in Tables I and II. Criteria such as cost and budget are based on householders' income [29]; and energy demand urgency and comfort level are associated with the consumers' lifestyle [6, 18, 33].

There are three factors to consider when measuring comfort conditions and determining the occupants' quality of life in a building. These factors are visual comfort, Indoor Air Quality (IAQ) and Thermal comfort [5, 39]. The visual comfort is calculated based on the illumination level of the building environment while IAQ is measureable by calculating ventilation rates and $\mathrm{CO}_{2}$ concentration [39].

The two major indices for evaluating thermal comfort are Predicted Mean Vote (PMV) and Predicted Percentage of Dissatisfied (PPD) [40]. As people are different in sensing thermal environment, it would be very difficult to keep all the occupants comfortable in a specific time and space. For this reason, the international standard, ISO 7730, the American Society of Heating Refrigerating and Air Conditioning Engineers (ASHRAE) standard, ANSI/ASHRAE Standard 55-2010 [41] have provided a method of calculating these indices for analytical determination of desirable thermal comfort in indoor environment. According to our literature review, there are two categories of researches for evaluating the effects of the comfort factor in the energy management of a building. The first group includes approaches such as those of $[10,42]$ that have considered the occupants' comfort factor only in terms of variables such as indoor temperature. However, they have not included the PMV index in their solutions. The second category is dealt with in studies such as $[5,39,43,44]$ who have used the PMV index to determine thermal comfort in addition to visual comfort and IAQ in their approaches for measuring the comfort level. In this proposal, it is assumed that the same methodologies as those utilized in $[5,39,45]$ are used for evaluating the comfort level criterion.

Another criterion that is evaluated in this approach is occupancy level. By 'occupancy' we mean the occupancy statistics in a specific zone at any given time. This criterion can be measured by a stochastic agent-based approach such as the one presented in [46] while the algorithm and methodology proposed by [47] can be used to address the solution for tracking multiple occupants and separately identifying them.

As the concept of smart grid aims to support "green" resources [1] and the emission trading scheme and carbon tax policy are designed to impact the energy demand [48], several criteria have been identified in relation to consumer's attitudes and behaviour towards the green electricity market $[49,50]$ on issues such as green gas emission, carbon tax and energy efficiency score.

According to the above discussion, the architecture of a multi-agent intelligent decision making support system for smart home is proposed in Figure 1. In this proposal, home EMS is a multi-agent system that consists of agents dedicated to measure the decision making criteria. The intelligent decision support agent will receive dynamic price signals from the utility provider by means of smart meters and it will act in accordance to the proposed fuzzy TOPSIS method for including the occupants' preferences during load energy management under demand response program. 


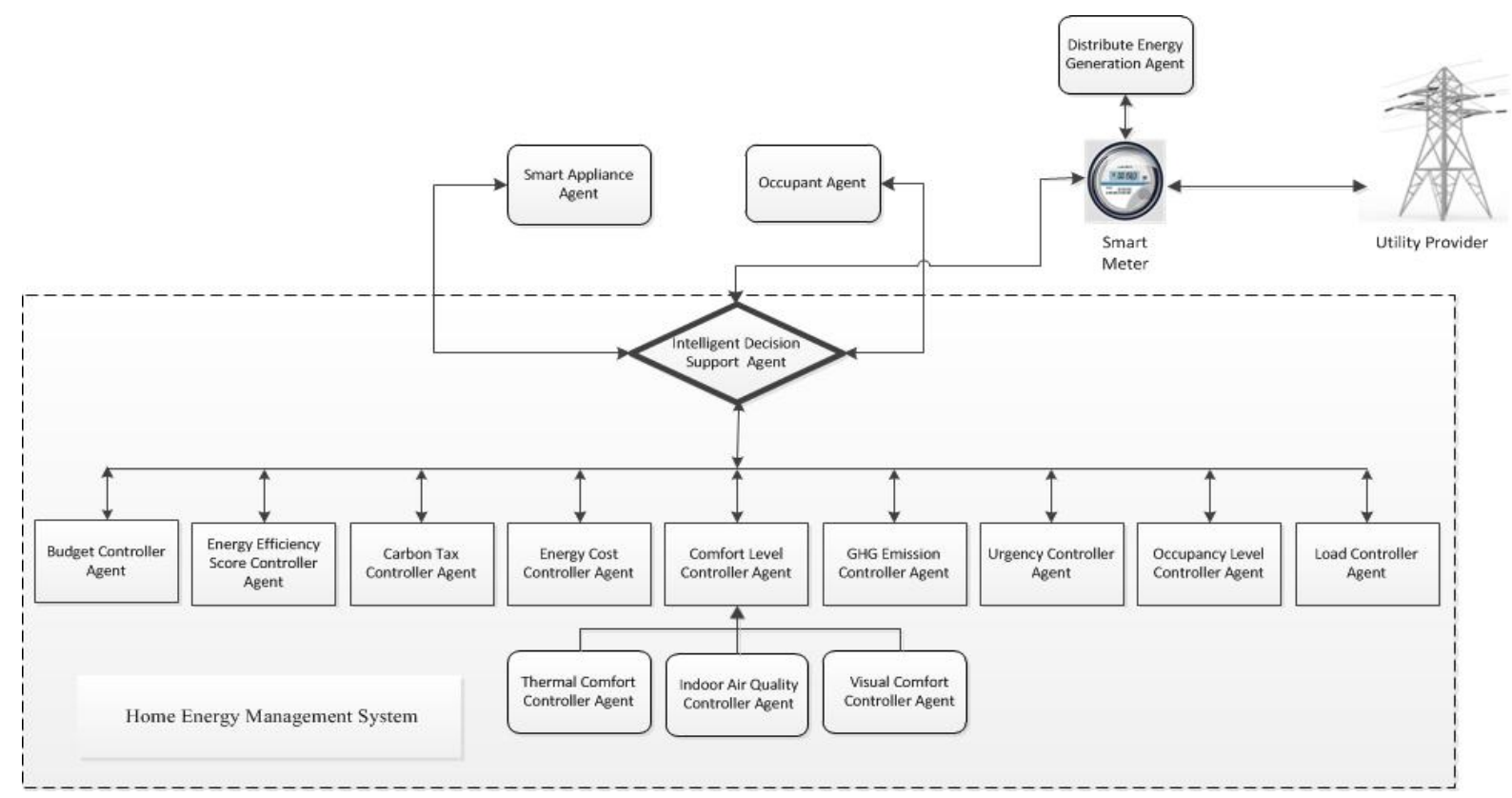

Fig. 1. Architecture of proposed multi-agent intelligent decision making support system (IDMSS) for smart home in smart grid

Two types of criteria are presented in Table I and II. The criteria with increasing values produce profit (positive) for consumers such as energy efficiency so more is better; and the other type is those ones that by increasing values produce more cost (negative) such as energy cost. Therefore, we try to decrease cost and increase profit when making decisions. This logic will be considered in formulating of variables in next section. The next section presents a methodology for decision making when occupants are considered as agents and they have communication with other agents shown in Figure I.

TABLE I. CRITERIA FOR EVALUATION OF ENERGY CONSUMPTION IN HOME AREAS

\begin{tabular}{|c|c|c|c|}
\hline & Criterion & Definition & Type \\
\hline $\mathrm{c}_{1}$ & Energy Cost & $\begin{array}{l}\text { Energy consumption cost of all } \\
\text { electrical devices in area } A_{i} \text { in time slot } \\
t_{1}\end{array}$ & - \\
\hline $\mathrm{c}_{2}$ & Budget & $\begin{array}{l}\text { The amount of budget that users are } \\
\text { prepared to expend on utilizing the } \\
\text { appliances in area } A_{i}\end{array}$ & - \\
\hline $\mathrm{c}_{3}$ & Urgency & $\begin{array}{l}\text { Energy demand urgency for each area } \\
\text { in time slot } t_{1}\end{array}$ & - \\
\hline $\mathrm{c}_{4}$ & Comfort level & $\begin{array}{l}\text { The comfort level for each area in time } \\
\text { slot } t_{1}\end{array}$ & + \\
\hline $\mathrm{C}_{5}$ & GHG emission & $\begin{array}{l}\text { Greenhouse gas emissions that are } \\
\text { produced by consumption in areas }\end{array}$ & - \\
\hline $\mathrm{c}_{6}$ & $\begin{array}{l}\text { Energy } \\
\text { efficiency score }\end{array}$ & $\begin{array}{l}\text { Energy efficiency rate provided for } \\
\text { users that can be compared with data } \\
\text { for neighbors and other households (in } \\
\text { social network or in a region) }\end{array}$ & + \\
\hline $\mathrm{c}_{7}$ & Carbon tax & $\begin{array}{l}\text { The amount of carbon tax allocated to } \\
\text { areas by consumed energy }\end{array}$ & - \\
\hline $\mathrm{c}_{8}$ & Occupancy level & $\begin{array}{l}\text { Amount of time that a dwelling is } \\
\text { occupied. }\end{array}$ & + \\
\hline
\end{tabular}

TABLE II. CRITERIA FOR EVALUATION OF APPLIANCES LOCATED IN AN AREA

\begin{tabular}{|l|l|l|l|}
\hline & Criterion & Definition & Type \\
\hline$c_{1}$ & Cost & $\begin{array}{l}\text { Energy consumption cost of a electrical } \\
\text { device in time slot } t_{1}\end{array}$ & - \\
\hline$c_{2}$ & $\begin{array}{l}\text { Adjusting } \\
\text { demand }\end{array}$ & $\begin{array}{l}\text { Flexibiklity of shifting their demand to off- } \\
\text { peak hours }\end{array}$ & + \\
\hline$c_{3}$ & Urgency & $\begin{array}{l}\text { Urgency of running an appliance in time } \\
\text { slot } \mathrm{t}_{1}\end{array}$ & - \\
\hline $\mathrm{c}_{4}$ & Enjoyment & $\begin{array}{l}\text { The level of pleasure that will be obtained } \\
\text { by usage in time slot } \mathrm{t}_{1}\end{array}$ & + \\
\hline
\end{tabular}




\section{Topsis: Technique For ORder Preference By Similarity To Ideal Solution}

\section{A. Methodology}

To arrive at an effective means of obtaining householders' preferences for utilizing appliances in a realtime pricing scheme of smart grid [51], and to better understand the energy distribution flow in a home EMS, this paper focuses on different areas of a home where groups of electrical devices are likely to be located. These areas are the alternatives in our decision-making model when householders want to decide how to distribute energy consumption flow. Then, we ask householders to specify their preferred appliances in each area. Therefore, this approach proposes two sets of criteria for decision-making: the first criteria for evaluating energy distribution in specific areas and the second set for appliance ranking. In this paper, we demonstrate this ranking only in the home environment.

Of the many multiple-criteria-decision-making (MCDM) methods, TOPSIS is a practical and useful technique for ranking and selecting a number of possible alternatives by measuring Euclidean distances. TOPSIS, developed by Hwang and Yoon [52], is a simple ranking method in conception and application [23]. The working principle of fuzzy TOPSIS is based on the fact that the selected alternative should have the shortest distance from the fuzzy positive ideal solution (FPIS) and the farthest from the fuzzy negative ideal solution (FNIS) for solving MCDM problems. As a result, the ideal solution comprises all the best criteria, whereas the negative ideal solution is made up of all the worst attainable criteria [53].

The stepwise procedure of implementing fuzzy TOPSIS is presented in Figure 2. By forming an initial decision matrix, the normalizing procedure of the decision matrix can begin. This is followed by building the weighted normalized decision matrix in Step 5, computing the fuzzy positive ideal solution (FPIS) and fuzzy negative ideal solution (FNIS) in Step 6, and calculating the separation measures for each alternative in Step 7. The procedure ends with the computation of the relative closeness coefficient in Step 8. The set of alternatives can be ranked according to the descending order of the closeness coefficient in Step 9.

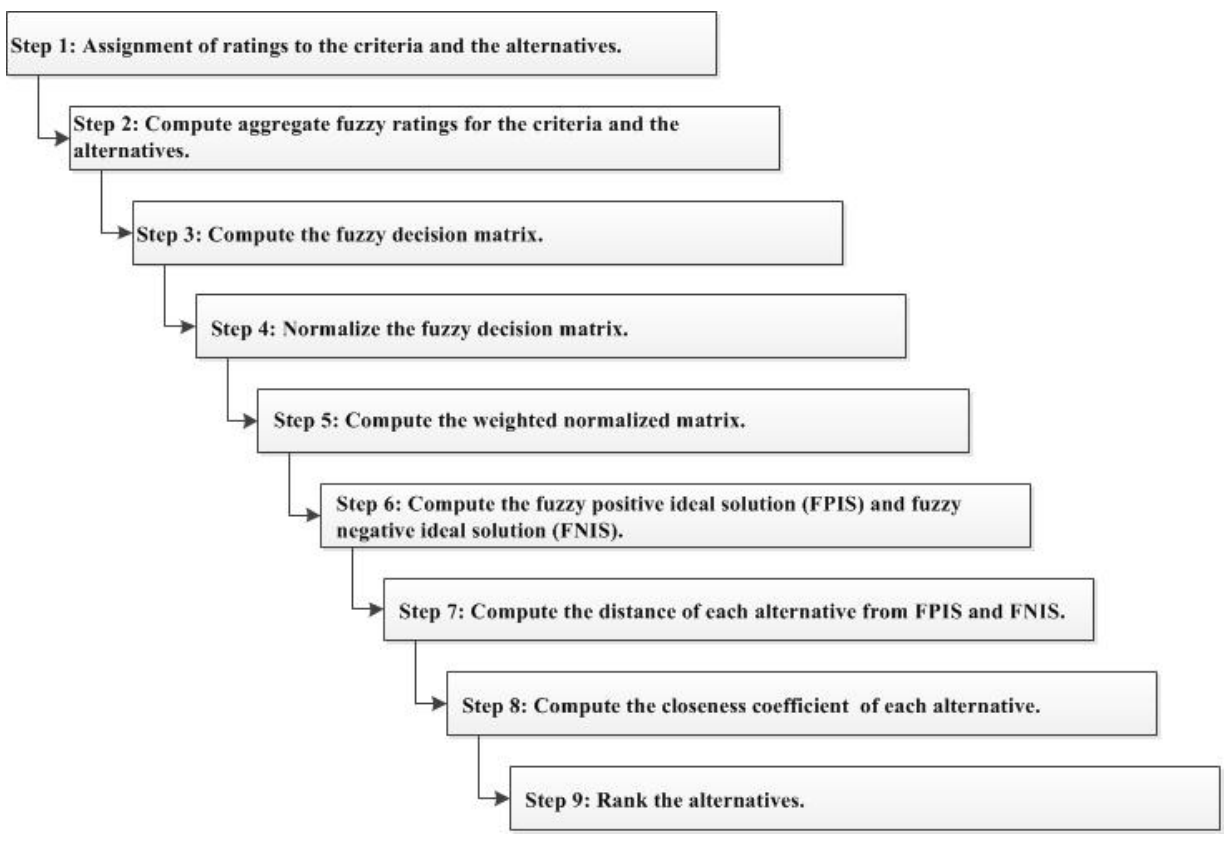

Fig. 2. Flow chart of the proposed Fuzzy TOPSIS method. 
The aim of this paper is to determine which part of a home is the area where appliances are most required when the price of energy unit is changed in a slot time; this is the area where users want the least load curtailment.

The steps of the fuzzy TOPSIS algorithm are as follows:

\section{Step 1: Assignment of ratings to the criteria and the alternatives}

Let us assume there are $j$ possible home areas called $A=\left\{A_{1}, A_{2}, \ldots A_{j}\right\}$ which are evaluated against $n$ criteria, $C=\left\{C_{1}, C_{2}, \ldots, C_{i}\right\}$. The criteria weights are denoted by $w_{i}(i=1,2, \ldots, m)$. The ratings of each consumer (family member) as a decision-maker $D_{k}=(k=1,2, \ldots, k)$ for each alternative or home area $A_{k j}=(j=1,2, \ldots, n)$ with respect to criteria $C_{i}(i=1,2, \ldots, m)$ are denoted by $\tilde{R}_{k}=\tilde{x}_{i j k}$ with membership function $\mu_{\tilde{R}_{k}}(x)$.

Step 2: Compute aggregate fuzzy ratings for the criteria and the alternatives.

If the fuzzy rating of all consumers or family members is represented as a triangular fuzzy number $\tilde{R}_{k}=\left(a_{k}, b_{k}, c_{k}\right), k=1,2, \ldots, K$, then the aggregated fuzzy rating is given by $\tilde{R}=(a, b, c), k=$ $1,2, \ldots, K$ where

$$
a=\min _{k}\left\{a_{k}\right\} \quad b=\frac{1}{k} \sum_{k=1}^{k} b_{k} \quad c=\max _{k}\left\{c_{k}\right\}
$$

If the fuzzy rating and importance weight of the $k$ th consumer are $\tilde{x}_{i j k}=\left(a_{i j k}, b_{i j k}, c_{i j k}\right)$ and $\widetilde{w}_{i j k}=$ $\left(w_{j k 1}, w_{j k 2}, w_{j k 3}\right), \mathrm{i}=1,2, \ldots, \mathrm{m}, \mathrm{j}=1,2, \ldots, \mathrm{n}$ respectively, then the aggregated fuzzy ratings $\tilde{x}_{i j k}$ of home areas with respect to each criteria are given by $\tilde{x}_{i j}=\left(a_{i j}, b_{i j}, c_{i j}\right)$ where

$$
\begin{aligned}
& a_{i j}=\min _{k}\left\{a_{i j k}\right\} ; b_{i j}=\frac{1}{k} \sum_{k=1}^{k} b_{i j k} \\
& c_{i j}=\max _{k}\left\{c_{i j k}\right\}
\end{aligned}
$$

The aggregated fuzzy weights $\left(\widetilde{w}_{i j}\right)$ of each criterion are calculated as $\widetilde{w}_{i j}=\left(w_{j 1}, w_{j 2}, w_{j 3}\right)$ where $w_{j 1}=\min _{k}\left\{w_{j k 1}\right\} ; w_{j 2}=\frac{1}{k} \sum_{k=1}^{k} w_{j k 2}$

$w_{j 3}=\max _{k}\left\{w_{j k 3}\right\}$

\section{Step 3: Compute the fuzzy decision matrix.}

The fuzzy decision matrix for the alternatives (home areas) $(\widetilde{D})$ and the criteria $(\widetilde{W})$ is constructed as follows:

$$
\begin{aligned}
& \widetilde{D}=\begin{array}{c}
A_{1} \\
A_{. .} \\
A_{m}
\end{array}\left[\begin{array}{ccc}
\tilde{x}_{11} & \cdots & \tilde{x}_{1 n} \\
\vdots & \ddots & \vdots \\
\tilde{x}_{m 1} & \cdots & \tilde{x}_{m n}
\end{array}\right] \\
& \widetilde{W}=\left(\widetilde{w}_{1}, \widetilde{w}_{2}, \ldots, \widetilde{w}_{n}\right)
\end{aligned}
$$

Step 4: Normalize the fuzzy decision matrix. 
The raw data are normalized to convert the various criteria scales into a comparable scale. The normalized fuzzy decision matrix is $\tilde{R}$ given by:

$\tilde{R}=\left[\tilde{r}_{i j}\right]_{m \times n}, i=1,2, \ldots, m ; j=1,2, \ldots, n$

Where

$\tilde{r}_{i j}=\left(\frac{a_{i j,}}{c_{j}^{+}}, \frac{b}{c_{j}^{+}}, \frac{c_{i j,}}{c_{j}^{+}}\right)$

and $c_{j}^{+}=\max _{i} c_{i j}$ (benefit criteria)

$\tilde{r}_{i j}=\left(\frac{a_{j}^{-}}{c_{i j}}, \frac{a_{j}^{-}}{b_{i j}}, \frac{a_{j}^{-}}{a_{i j}}\right)$

and $a_{j}^{-}=\operatorname{maxmin}_{i} a_{i j}$ (cost criteria)

Step 5: Compute the weighted normalized matrix.

The weighted normalized matrix $\tilde{V}$ for criteria is computed by multiplying the weights $\left(\widetilde{w}_{j}\right)$ of evaluation criteria with the normalized fuzzy decision matrix normalization of the decision matrix $\tilde{r}_{i j}$ $\tilde{V}=\left[\tilde{v}_{i j}\right]_{m \times n} i=1,2, \ldots, m ; j=1,2, \ldots, n$ where $\tilde{v}_{i j}=\tilde{r}_{i j} \times \widetilde{w}_{i j}$

Step 6: Compute the fuzzy positive ideal solution (FPIS) and fuzzy negative ideal solution (FNIS)

The FPIS and FNIS of the alternatives is computed as follows:

$A^{+}=\left(\tilde{v}_{1}^{+}, \tilde{v}_{2}^{+}, \ldots, \tilde{v}_{n}^{+}\right)$

Where

and

$$
\tilde{v}_{j}^{+}=\max _{i}\left\{v_{i j 3}\right\}, \mathrm{i}=1,2, \ldots, \mathrm{m}, \quad \mathrm{j}=1,2, \ldots, \mathrm{n}
$$

$$
A^{-}=\left(\tilde{v}_{1}^{+}, \tilde{v}_{2}^{+}, \ldots, \tilde{v}_{n}^{+}\right)
$$

Where

$$
\tilde{v}_{j}^{-}=\min _{i}\left\{v_{i j 1}\right\}, \mathrm{i}=1,2, \ldots, \mathrm{m}, \quad \mathrm{j}=1,2, \ldots, \mathrm{n}
$$

Step 7: Compute the distance of each alternative from FPIS and FNIS.

The distance $\left(d_{i}^{+}, d_{i}^{-}\right)$of each weighted alternative $i=1,2, \ldots, m$ from the FPIS and the FNIS is computed as follows:

$d_{i}^{+}=\sum_{j=1}^{n} d_{v}\left(\tilde{v}_{i j}, \tilde{v}_{i j}^{+}\right), i=1,2, \ldots, m$

$d_{i}^{-}=\sum_{j=1}^{n} d_{v}\left(\tilde{v}_{i j}, \tilde{v}_{i j}^{-}\right), i=1,2, \ldots, m$

Where $d_{v}(\tilde{a}, \tilde{b})$ is the distance measurement between two fuzzy numbers $\tilde{a}$ and $\tilde{b}$.

Step 8: Compute the closeness coefficient $\left(C C_{i}\right)$ of each

alternative. 
The closeness coefficient $C C_{i}$ represents the distances to the fuzzy positive ideal solution $\left(A^{+}\right)$and the fuzzy negative ideal solution $\left(A^{-}\right)$simultaneously. The closeness coefficient of each alternative is calculated by:

$$
\left(C C_{i}\right)=\frac{d_{i}^{-}}{d_{i}^{-}+d_{i}^{+}} \mathrm{i}=1,2, \ldots, \mathrm{m}
$$

\section{Step 9: Rank the alternatives or home areas.}

In Step 9, the different alternatives (home areas) are ranked according to the closeness coefficient $\left(C C_{i}\right)$ in decreasing order. The best alternative is closest to the FPIS and farthest from the FNIS.

\section{Simulation Results}

Using the above analysis, this paper describes a scenario to demonstrate the fuzzy TOPSIS methodology [51]. In this scenario, the conversion scale is applied to transform the linguistic terms for determining the rating of alternatives and criteria into fuzzy numbers as shown by the fuzzy triangular membership function in Figure 3.

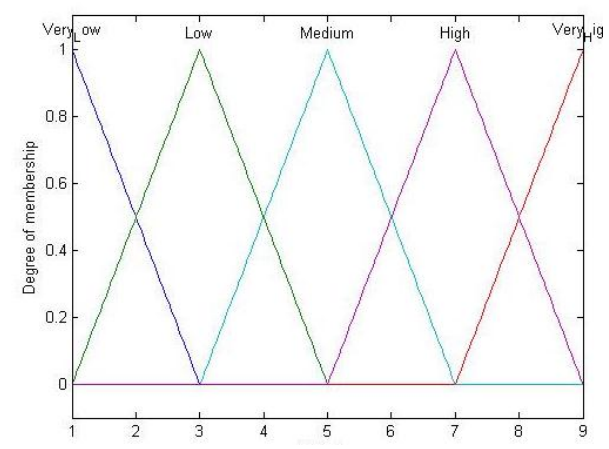

Fig. 3. Fuzzy triangular membership function.

In this scenario, there are two occupants in a house. They are from different cultural backgrounds and have different incomes: user 1 does not care about cost and wants a high level of comfort through energy utilization; user 2 is concerned about environmental issues and is a green consumer. Both have received energy consumption information via a home EMS. This information includes the cost of energy, carbon tax and GHG emission in the home areas of $A_{1}=$ Kitchen, $A_{2}=$ Bedrooms, $A_{3}=$ Living room and $A_{4}=$ Laundry and the information is used to compare the efficiency of their consumption with that of their neighbors. So, a decision on energy allocation should be made when the unit price of electrical energy increases from the slot time of $t_{i}$ to $t_{i+1}$. The users use linguistic assessment to rate the criteria (Table III). For example, user 1 believes that the importance of energy cost is high but user 2 believes that it is very high or the importance of the carbon tax for user 1 is at medium but it is high for user 2 and so forth. To construct the fuzzy TOPSIS model, the first step is the linguistic assessment of criteria and alternatives and the computation of the aggregated fuzzy value using (1) and (2) the results of which are presented in Tables III, IV and V. For example, in Table III for criterion $c_{2}$, "budget", user 1 is satisfied to allocate a medium amount of budget for energy for fuzzy triangular number that is $(3,5,7)$, but user 2 likes to spend a high amount of budget for energy for the fuzzy triangular number of $(5,7,9)$, so the aggregated fuzzy 
weight is given by $\widetilde{w}_{2}=\left(w_{21}, w_{22}, w_{23}\right)$ where: $\mathrm{W}_{21}=\operatorname{MIN}_{2}(3,5)=3 ; \mathrm{W}_{22}=\frac{1}{2}(5+7)=6 ; w_{23}=$ $\max _{2}(7,9)=9 ; \quad \widetilde{w}_{2}=(3,6,9)$ In Step 4 , we normalize the fuzzy decision matrix of the alternative using (8); the result is shown in Table VI. The weighted decision matrix in Step 5 is obtained by (8). The result is shown in Table VII below.

TABLE III. LINGUISTIC ASSESSMENT FOR CRITERIA

\begin{tabular}{|c|c|c|c|c|}
\hline \multicolumn{2}{|c|}{ Criteria } & \multirow{2}{*}{\multicolumn{2}{|c|}{ Users }} & \multirow{3}{*}{$\begin{array}{l}\text { Aggregated } \\
\text { fuzzy weight }\end{array}$} \\
\hline & & & & \\
\hline & & User 1 & User 2 & \\
\hline $\mathrm{c}_{1}$ & Energy Cost & $\mathrm{H}$ & $\mathrm{VH}$ & $(5,8,9)$ \\
\hline $\mathrm{c}_{2}$ & Budget & $\mathrm{M}$ & $\mathrm{H}$ & $(3,6,9)$ \\
\hline $\mathrm{c}_{3}$ & Urgency & $\mathrm{H}$ & $\mathrm{M}$ & $(3,6,9)$ \\
\hline $\mathrm{c}_{4}$ & Comfort level & $\mathrm{VH}$ & M & $(3,7,9)$ \\
\hline$c_{5}$ & GHG emission & VL & $\mathrm{VH}$ & $(1,5,9)$ \\
\hline $\mathrm{c}_{6}$ & Energy efficiency score & $\mathrm{L}$ & $\mathrm{VH}$ & $(1,6,9)$ \\
\hline$c_{7}$ & Carbon tax & M & $\mathrm{H}$ & $(3,6,9)$ \\
\hline $\mathrm{c}_{8}$ & Occupancy level & $\mathrm{H}$ & $\mathrm{H}$ & $(5,7,9)$ \\
\hline
\end{tabular}

TABLE IV. LINGUISTIC ASSESSMENT FOR ALTERNATIVES

\begin{tabular}{|c|c|c|c|c|c|c|c|c|}
\hline \multirow[t]{2}{*}{ CRITERIA } & \multicolumn{2}{|c|}{ A1 } & \multicolumn{2}{|c|}{$\mathrm{A} 2$} & \multicolumn{2}{|c|}{ A3 } & \multicolumn{2}{|c|}{ A4 } \\
\hline & U1 & $\mathrm{U} 2$ & U1 & $\mathrm{U} 2$ & U1 & $\mathrm{U} 2$ & U1 & $\mathrm{U} 2$ \\
\hline$c_{1}$ & $\mathrm{H}$ & $\mathrm{M}$ & $\mathrm{M}$ & $\mathrm{H}$ & $\mathrm{M}$ & $\mathrm{VH}$ & $\mathrm{L}$ & $\mathrm{H}$ \\
\hline$c_{2}$ & $\mathrm{~L}$ & $\mathrm{VH}$ & $\mathrm{M}$ & $\mathrm{L}$ & $\mathrm{H}$ & $\mathrm{L}$ & $\mathrm{H}$ & $\mathrm{L}$ \\
\hline$c_{3}$ & $\mathrm{M}$ & $\mathrm{H}$ & $\mathrm{M}$ & $\mathrm{L}$ & $\mathrm{M}$ & $\mathrm{L}$ & $\mathrm{VH}$ & $\mathrm{M}$ \\
\hline$c_{4}$ & $\mathrm{VH}$ & $\mathrm{M}$ & $\mathrm{VH}$ & $\mathrm{M}$ & $\mathrm{VH}$ & $\mathrm{H}$ & $\mathrm{L}$ & VL \\
\hline$c_{5}$ & $\mathrm{~L}$ & $\mathrm{H}$ & $\mathrm{M}$ & $\mathrm{H}$ & $\mathrm{L}$ & $\mathrm{VH}$ & VL & $\mathrm{VH}$ \\
\hline$c_{6}$ & $\mathrm{~L}$ & $\mathrm{M}$ & $\mathrm{H}$ & $\mathrm{H}$ & $\mathrm{L}$ & $\mathrm{VH}$ & VL & $\mathrm{H}$ \\
\hline$c_{7}$ & $\mathrm{M}$ & $\mathrm{M}$ & $\mathrm{M}$ & $\mathrm{VH}$ & $\mathrm{L}$ & VL & $\mathrm{M}$ & $\mathrm{H}$ \\
\hline$c_{8}$ & VH & $\mathrm{M}$ & $\mathrm{L}$ & VL & VL & $\mathrm{M}$ & $\mathrm{L}$ & $\mathrm{M}$ \\
\hline
\end{tabular}

TABLE V. AGGREGATE FUZZY DECISION MATRIX

\begin{tabular}{|c|c|c|c|c|}
\hline CRITERIA & $\mathrm{A} 1$ & $\mathrm{~A} 2$ & $\mathrm{~A} 3$ & $\mathrm{~A} 4$ \\
\hline $\mathrm{c}_{1}$ & $(3,6,9)$ & $(3,6,9)$ & $(3,7,9)$ & $(1,5,9)$ \\
\hline $\mathrm{c}_{2}$ & $(1,6,9)$ & $(1,4,7)$ & $(1,4,7)$ & $(1,4,7)$ \\
\hline $\mathrm{c}_{3}$ & $(3,6,9)$ & $(1,4,7)$ & $(1,4,7)$ & $(3,7,9)$ \\
\hline $\mathrm{c}_{4}$ & $(3,7,9)$ & $(3,7,9)$ & $(3,7,9)$ & $(1,2,5)$ \\
\hline $\mathrm{c}_{5}$ & $(1,5,9)$ & $(3,6,9)$ & $(1,6,9)$ & $(1,5,9)$ \\
\hline $\mathrm{c}_{6}$ & $(1,4,7)$ & $(7,9,9)$ & $(1,6,9)$ & $(1,4,9)$ \\
\hline $\mathrm{c}_{7}$ & $(3,5,7)$ & $(3,7,9)$ & $(1,2,5)$ & $(3,6,9)$ \\
\hline $\mathrm{c}_{8}$ & $(3,7,9)$ & $(1,2,5)$ & $(1,3,7)$ & $(1,4,7)$ \\
\hline
\end{tabular}


TABLE VI. NORMALIZED FUZZY DECISION MATRIX FOR ALTERNATIVES

\begin{tabular}{|c|c|c|c|c|}
\hline CRITERIA & $\mathrm{A} 1$ & $\mathrm{~A} 2$ & $\mathrm{~A} 3$ & $\mathrm{~A} 4$ \\
\hline $\mathrm{c}_{1}$ & $(0.11,0.17,033)$ & $(0.11,0.17,033)$ & $(0.11,0.14,0.33)$ & $(0.11,0.2,1.00)$ \\
\hline $\mathrm{c}_{2}$ & $(0.11,0.17,1.00)$ & $(0.14,0.25,1.00)$ & $(0.14,0.25,1.00)$ & $(0.14,0.25,1.00)$ \\
\hline $\mathrm{c}_{3}$ & $(0.11,0.17,033)$ & $(0.14,0.25,1.00)$ & $(0.14,0.25,1.00)$ & $(0.11,0.14,0.33)$ \\
\hline $\mathrm{c}_{4}$ & $(0.33,0.78,1.00)$ & $(0.33,0.78,1.00)$ & $(0.33,0.78,1.00)$ & $(0.11,0.22,0.56)$ \\
\hline $\mathrm{c}_{5}$ & $(0.11,0.20,1.00)$ & $(0.11,0.17,033)$ & $(0.11,0.17,1.00)$ & $(0.11,0.20,1.00)$ \\
\hline $\mathrm{c}_{6}$ & $(0.11,0.44,0.78)$ & $(0.78,1.00,1.00)$ & $(0.11,0.67,1.00)$ & $(0.11,0.44,0.100)$ \\
\hline $\mathrm{c}_{7}$ & $(0.14,0.20,0.33)$ & $(0.11,0.14,0.33)$ & $(0.20,0.50,1.00)$ & $(0.11,0.17,033)$ \\
\hline $\mathrm{c}_{8}$ & $(0.33,0.78,1.00)$ & $(0.11,0.22,0.56)$ & $(0.11,0.33,0.78)$ & $(0.11,0.44,0.78)$ \\
\hline
\end{tabular}

TABLE VII. WEIGHTED NORMALIZED FUZZY DECISION MATRIX

\begin{tabular}{|c|c|c|c|c|}
\hline CRITERIA & $\mathrm{A} 1$ & $\mathrm{~A} 2$ & $\mathrm{~A} 3$ & $\mathrm{~A} 4$ \\
\hline $\mathrm{c}_{1}$ & $(0.56,1.33,3)$ & $(0.56,1.33,3)$ & $(0.56,1.14,3)$ & $(0.56,1.6,9.00)$ \\
\hline $\mathrm{c}_{2}$ & $(0.33,1.00,9.00)$ & $(0.43,1.5,9.00)$ & $(0.43,0.15,9.0)$ & $(0.43,1.6,9.00)$ \\
\hline $\mathrm{c}_{3}$ & $(0.33,1.00,3.00)$ & $(0.43,1.5,9.00)$ & $(0.43,0.15,9.00)$ & $(0.33,0.86,3.00)$ \\
\hline $\mathrm{c}_{4}$ & $(1.00,5.44,9.00)$ & $(1.00,5.44,9.00)$ & $(1.00,5.44,9.00)$ & $(0.33,1.56,5.00)$ \\
\hline $\mathrm{c}_{5}$ & $(0.11,1.00,9.00)$ & $(0.11,0.83,3.00)$ & $(0.11,0.83,9.00)$ & $(0.11,1.00,9.00)$ \\
\hline $\mathrm{c}_{6}$ & $(0.11,2.67,7.00)$ & $(0.78,6.00,9.00)$ & $(0.11,4.00,9.00)$ & $(0.11,2.67,9.00)$ \\
\hline $\mathrm{c}_{7}$ & $(0.43,1.20,3.00)$ & $(0.33,0.86,3.00)$ & $(0.60,3.00,9.00)$ & $(0.33,1.00,3.00)$ \\
\hline $\mathrm{c}_{8}$ & $(1.67,5.44,9.00)$ & $(0.56,1.56,5.00)$ & $(0.56,2.33,7.00)$ & $(0.56,3.11,7.00)$ \\
\hline
\end{tabular}

The fuzzy positive ideal solution (FPIS) and fuzzy negative ideal solution (FNIS) are obtained by (9) and (10) and then the distances of each alternative from FPIS and FNIS are obtained by using (11) and (12) as shown in Table VIII. The closeness coefficient of each alternative is calculated by (13) and is represented in Table VIIII. The alternative with the higher value is preferred. Hence, the ranking of alternatives is 1Laundry, 2-Bedrooms, 3- Kitchen, 4- Living room. This ranking shows the users' preferences for energy distribution flow to the home areas or group of appliances in accordance with increases in the energy unit price.

Table VIIII. ranking according to the closeness coefficient

Table VIII. Distance of each alternative from FPIS and FNIS

\begin{tabular}{|c|c|c|c|c|}
\hline & A1 & A2 & A3 & A4 \\
& Kitchen & Bedrooms & Living room & Laundry \\
\hline $\mathrm{CC}_{\mathrm{i}}$ & 0.3587 & 0.3602 & 0.3539 & 0.3742 \\
\hline Ranking & 3 & 2 & 4 & 1 \\
\hline
\end{tabular}

\begin{tabular}{|l|c|c|c|c|c|c|c|c|}
\hline \multirow{2}{*}{} & \multicolumn{5}{|c|}{$d_{i}^{-}$} & \multicolumn{4}{|c|}{$d_{i}^{+}$} \\
\cline { 2 - 9 } & $\boldsymbol{A 1}$ & $\boldsymbol{A 2}$ & $\boldsymbol{A 3}$ & $\boldsymbol{A 4}$ & $\boldsymbol{A 1}$ & $\boldsymbol{A 2}$ & $\boldsymbol{A 3}$ & $\boldsymbol{A 4}$ \\
\hline$c_{1}$ & 1.48 & 1.64 & 1.45 & 4.91 & 7.44 & 7.44 & 7.50 & 6.48 \\
\hline$c_{2}$ & 5.01 & 5.04 & 5.04 & 5.04 & 6.81 & 6.57 & 6.57 & 6.57 \\
\hline$c_{3}$ & 1.58 & 5.04 & 5.04 & 1.56 & 7.64 & 6.57 & 6.57 & 7.69 \\
\hline$c_{4}$ & 5.82 & 6.00 & 5.82 & 2.78 & 5.05 & 5.04 & 5.05 & 6.98 \\
\hline$c_{5}$ & 5.15 & 1.71 & 5.14 & 5.15 & 6.90 & 7.78 & 6.96 & 6.90 \\
\hline$c_{6}$ & 4.24 & 5.98 & 5.60 & 5.34 & 6.40 & 5.05 & 5.88 & 6.30 \\
\hline$c_{7}$ & 1.62 & 1.42 & 5.23 & 1.58 & 7.53 & 7.69 & 5.96 & 7.64 \\
\hline$c_{8}$ & 5.67 & 3.04 & 3.86 & 4.00 & 4.70 & 6.89 & 6.31 & 6.05 \\
\hline$\Sigma$ & 30.59 & 29.92 & 37.21 & 30.40 & 52.49 & 53.07 & 50.85 & 54.64 \\
\hline
\end{tabular}




\section{CONCLUSION}

The main purpose of this paper is to present a methodology to include most of the significant variables effective in decision making process for building energy consumption management. This is done to prioritize the utilization of the groups of appliances located in a specific zone when the function of occupants' utility is significant in load curtailment in demand response programs. A multi-agent based model is proposed for measuring economic, social, cultural and environmental factors that affect users' consumption behavior. Users with different backgrounds choose different linguistic terms to evaluate their consumption. Hence, the fuzzy TOPSIS methodology proposed in this paper is a tool that can support a group of household members, considered as agents, to assess their consumption and to make decisions about energy flow distribution. This methodology can be applied for ranking the appliances in a home area by using the criteria presented in Table II. Note that in this approach, we assumed that detailed information such as users' price signals and consumption profiles will be provided by the agents presented in Figure 1. Therefore, for future research it is recommended to implement a multi-agent based simulation for analyzing and predicting the users' consumption behavior.

\section{REFERENCES}

[1] O. A. Sianaki, O. Hussain, T. Dillon, and A. R. Tabesh, "Intelligent Decision Support System for Including Consumers' Prefere nces in Residential Energy Consumption in Smart Grid",", in Computational Intelligence, Modelling and Simulation (CIMSiM), 2010 Second International Conference on, 2010, pp. 154-159.

[2] R. Fazal, J. Solanki, and S. K. Solanki, "Demand response using multi-agent system"“, in North American Power Symposium (NAPS), 2012, pp. 1-6.

[3] M. A. S. Masoum, P. S. Moses, and S. Deilami, "Load management in smart grids considering harmonic distortion and transformer derating", in Innovative Smart Grid Technologies (ISGT), 2010, pp. 1-7.

[4] L. Klein, J.-y. Kwak, G. Kavulya, F. Jazizadeh, B. Becerik-Gerber, P. Varakantham, and M. Tambe, "Coordinating occupant behavior for building energy and comfort management using multi-agent systems", Automation in Construction, vol. 22, 2012, pp. 525-536.

[5] W. Lingfeng, W. Zhu, and Y. Rui, "Intelligent Multiagent Control System for Energy and Comfort Management in Smart and Sustainable Buildings", Smart Grid, IEEE Transactions on, vol. 3, pp. 605-617, 2012.

[6] O. A. Sianaki, O. Hussain, and A. R. Tabesh, "A Knapsack problem approach for achieving efficient energy consumption in smart grid for endusers' life style", in Innovative Technologies for an Efficient and Reliable Electricity Supply (CITRES), 2010 IEEE Conference on, 2010, pp. 159-164.

[7] J. Aghaei and M.-I. Alizadeh, "Demand response in smart electricity grids equipped with renewable energy sources: A review", Renewable and Sustainable Energy Reviews, vol. 18, pp. 64-72, 2013.

[8] S. J. Darby and E. McKenna, "Social implications of residential demand response in cool temperate climates", Energy Policy, vol. 49, pp. 759-769, 2012.

[9] C. Tiansong, H. Goudarzi, S. Hatami, S. Nazarian, and M. Pedram, "Concurrent optimization of consumer's electrical energy bill and producer's power generation cost under a dynamic pricing model”, in Innovative Smart Grid Technologies (ISGT), 2012 IEEE PES, 2012, pp. 1-6.

[10] M. Pipattanasomporn, M. Kuzlu, and S. Rahman, "An Algorithm for Intelligent Home Energy Management and Demand Response Analysis", Smart Grid, IEEE Transactions on, vol. PP, pp. 1-1, 2012.

[11] P. Carreira, V. Amaral, and B. Barroca, "The case for a systematic development of Building Automation Systems", in Innovative Smart Grid Technologies (ISGT Europe), 2011 2nd IEEE PES International Conference and Exhibition on, 2011, pp. 1-8.

[12] S. Chanana, "Demand response by dynamic demand control using frequency linked real-time prices", International journal of energy sector management, vol. 4, p. 44, 2010.

[13] A. Di Giorgio and L. Pimpinella, "An event driven Smart Home Controller enabling consumer economic saving and automated Demand Side Management”, Applied Energy, vol. 96, pp. 92-103, 2012.

[14] N. Gatsis and G. B. Giannakis, "Cooperative multi-residence demand response scheduling", in Information Sciences and Systems (CISS), 2011 45th Annual Conference on, 2011, pp. 1-6.

[15] N. Gudi, W. Lingfeng, V. Devabhaktuni, and S. S. S. R. Depuru, "Demand response simulation implementing heuristic optimization for home energy management", in North American Power Symposium (NAPS), 2010, 2010, pp. 1-6.

[16] P. Samadi, A. Mohsenian-Rad, R. Schober, V. W. S. Wong, and J. Jatskevich, "Optimal Real-Time Pricing Algorithm Based on Utility Maximization for Smart Grid", in Smart Grid Communications (SmartGridComm), 2010 First IEEE International Conference on, 2010, pp. 415-420.

[17] G. Wood and M. Newborough, "Dynamic energy-consumption indicators for domestic appliances: environment, behaviour and design", Energy and Buildings, vol. 35, pp. 821-841, 2003.

[18] Y. G. Yohanis, "Domestic energy use and householders' energy behaviour", Energy Policy, vol. 41, pp. 654-665, 2012. 
Z. Ziming, T. Jie, S. Lambotharan, C. Woon Hau, and F. Zhong, "An integer linear programming based optimization for home demand-side management in smart grid", in Innovative Smart Grid Technologies (ISGT), 2012 IEEE PES, 2012, pp. 1-5.

[20] B. Kaibin, F. Allerding, and H. Schmeck, "User behavior prediction for energy management in smart homes", in Fuzzy Systems and Knowledge Discovery (FSKD), 2011 Eighth International Conference on, 2011, pp. 1335-1339.

[21] I. Lampropoulos, G. M. A. Vanalme, and W. L. Kling, "A methodology for modeling the behavior of electricity prosumers within the smart grid", in Innovative Smart Grid Technologies Conference Europe (ISGT Europe), 2010 IEEE PES, 2010, pp. 1-8.

[22] G. R. Newsham and B. G. Bowker, "The effect of utility time-varying pricing and load control strategies on residential summer peak electricity use: A review", Energy Policy, vol. 38, pp. 3289-3296, 2010.

[23] M. Behzadian, S. Khanmohammadi Otaghsara, M. Yazdani, and J. Ignatius, "A state-of the-art survey of TOPSIS applications", Expert Systems with Applications, vol. 39, pp. 13051-13069, 2012.

[24] H. A. Aalami, M. P. Moghaddam, and G. R. Yousefi, "Modeling and prioritizing demand response programs in power markets", Electric Power Systems Research, vol. 80, pp. 426-435, 2010.

[25] W. Xiaodong, S. Limin, and Z. Changqin, "An interval multiple attribute decision-making model based on TOPSIS and it's application in smart grid evaluation", in Artificial Intelligence, Management Science and Electronic Commerce (AIMSEC), 2011 2nd International Conference on, 2011, pp. 4948-4951.

D. Nabouch, N. Matta, R. Rahim-Amoud, and L. Merghem-Boulahia, "An Agent-Based Approach for Efficient Energy Management in the Context of Smart Houses", in Highlights on Practical Applications of Agents and Multi-Agent Systems. vol. 365, J. Corchado, J. Bajo, J. Kozlak, P. Pawlewski, J. Molina, V. Julian, R. Silveira, R. Unland, and S. Giroux, Eds., ed: Springer Berlin Heidelberg, 2013, pp. 375-386. G. Rohbogner, S. Fey, U. J. J. Hahnel, P. Benoit, and B. Wille-Haussmann, "What the term agent stands for in the Smart Grid definition of agents and multi-agent systems from an engineer's perspective", in Computer Science and Information Systems (FedCSIS), 2012 Federated Conference on, 2012, pp. 1301-1305.

[28] P. O. FANGER, Thermal comfort: analysis and applications in environmental engineering. New York: McGraw-Hill, 1972.

[29] R. Kowsari and H. Zerriffi, "Three dimensional energy profile: A conceptual framework for assessing household energy use", Energy Policy, vol. 39, 2011, pp. 7505-7517.

[30] T. Hargreaves, M. Nye, and J. Burgess, "Keeping energy visible? Exploring how householders interact with feedback from smart energy monitors in the longer term", Energy Policy, vol. 52, 2013, pp 126-134.

P. C. Stern, "Information, Incentives, and Proenvironmental Consumer Behavior", Journal of Consumer Policy, vol. 22, pp. 461-478, 1999.

[32] A. H. Mohsenian-Rad, V. W. S. Wong, J. Jatskevich, and R. Schober, "Optimal and autonomous incentive-based energy consumption scheduling algorithm for smart grid", in Innovative Smart Grid Technologies (ISGT), 2010, 2010, pp. 1-6.

[33] C. Wang and M. d. Groot, "Managing end-user preferences in the smart grid", presented at the Proceedings of the 1st International Conference on Energy-Efficient Computing and Networking, Passau, Germany, 2010.

[34] T. Hargreaves, M. Nye, and J. Burgess, "Making energy visible: A qualitative field study of how householders interact with feedback from smart energy monitors", Energy Policy, vol. 38, pp. 6111-6119, 2010.

[35] S. Gottwalt, W. Ketter, C. Block, J. Collins, and C. Weinhardt, "Demand side management-A simulation of household behavior under variable prices", Energy Policy, vol. 39, pp. 8163-8174, 2011.

[36] T. Krishnamurti, D. Schwartz, A. Davis, B. Fischhoff, W. B. de Bruin, L. Lave, and J. Wang, "Preparing for smart grid technologies: A behavioral decision research approach to understanding consumer expectations about smart meters", Energy Policy, vol. 41, pp. 790-797, 2012.

[37] E. J. S. Plug and B. M. S. Van Praag, "Similarity in response behavior between household members: An application to income evaluation", Journal of Economic Psychology, vol. 19, 1998, pp. 497-513.

[38] Y. Yamamoto, A. Suzuki, Y. Fuwa, and T. Sato, "Decision-making in electrical appliance use in the home", Energy Policy, vol. 36, pp. 1679$1686,2008$.

[39] A. I. Dounis and C. Caraiscos, "Advanced control systems engineering for energy and comfort management in a building environment-A review", Renewable and Sustainable Energy Reviews, vol. 13, 2009, pp. 1246-1261.

[40] P. O. Fanger, "Thermal environment — Human requirements", Environmentalist, 1986/12/01 1986, vol. 6, pp. $275-278$.

[41] T. A. S. o. H. R. a. A. C. Engineers, "Thermal Environmental Conditions for Human Occupancy", ed. USA: American Society of Heating, Refrigerating and Air-Conditioning Engineers, Inc, 2005.

[42] D. Pengwei and L. Ning, "Appliance Commitment for Household Load Scheduling", Smart Grid, IEEE Transactions on, vol. 2, 2011, pp. 411419.

[43] D. Kolokotsa, D. Tsiavos, G. S. Stavrakakis, K. Kalaitzakis, and E. Antonidakis, "Advanced fuzzy logic controllers design and evaluation for buildings' occupants thermal-visual comfort and indoor air quality satisfaction", Energy and Buildings, vol. 33, pp. 531-543, 2001.

[44] D. L. Ha, H. Joumaa, S. Ploix, and M. Jacomino, "An optimal approach for electrical management problem in dwellings", Energy and Buildings, vol. 45, 2012, pp. 1-14.

[45] A. I. Dounis, M. J. Santamouris, C. C. Lefas, and A. Argiriou, "Design of a fuzzy set environment comfort system", Energy and Buildings, vol. 22, 1995, pp. 81-87.

[46] C. Liao, Y. Lin, and P. Barooah, "Agent-based and graphical modelling of building occupancy", Journal of Building Performance Simulation, vol. 5, 2012/01/01, pp. 5-25.

[47] A. S. Crandall, "Behaviometrics for multiple residents in a smart environment", 3460369 Ph.D., Washington State University, United States -- Washington, 2011.

[48] K. Mori, "Modeling the impact of a carbon tax: A trial analysis for Washington State", Energy Policy, vol. 48, pp. 627-639, 2012.

[49] L. Gan, G. S. Eskeland, and H. H. Kolshus, "Green electricity market development: Lessons from Europe and the US", Energy Policy, vol. 35, 2007, pp. 144-155.

[50] S. Salmela and V. Varho, "Consumers in the green electricity market in Finland", Energy Policy, vol. 34, 2006, pp. $3669-3683$.

[51] O. A. Sianaki and M. A. S. Masoum, "A fuzzy TOPSIS approach for home energy management in smart grid with considering householders' preferences", in Innovative Smart Grid Technologies (ISGT), 2013 IEEE PES, 2013, pp. 1-6.

[52] C. L. Hwang and K. P. Yoon, "Multiple attribute decision making: Methods and applications", Springer-Verlag, 1981.

[53] H. Zhang, C.-l. Gu, L.-w. Gu, and Y. Zhang, "The evaluation of tourism destination competitiveness by TOPSIS \&amp; information entropy - A case in the Yangtze River Delta of China", Tourism Management, vol. 32, 2011, pp. 443-451. 


\section{The Authors}

Omid Ameri Sianaki received the Bachelor degree in Mechanical Engineering in 2000 and Master degree in Operational Research from Azad University, Tehran, Iran in 2007 and is currently pursuing the $\mathrm{PhD}$ degree in Electrical and Computer Engineering from Curtin University, Perth, Western Australia. He is a member of IEEE from 2010. His research interests include demand response, intelligent decision making, mathematical modelling and optimization techniques.

Mohammad A.S. Masoum received his B.S., M.S. and Ph.D. degrees in Electrical and Computer Engineering in 1983, 1985, and 1991, respectively, from the University of Colorado, Boulder, USA. His research interests include optimization, power quality and stability of power systems and electric machines, as well as distributed generation. Dr. Masoum is the co-author of "Power Quality in Power Systems and Electrical Machines" (Elsevier, 2008) and "Power Conversion of Renewable Energy Systems" (Springer, 2011). Currently, he is a Professor and discipline leader for electrical engineering in the Electrical and Computer Engineering Department, Curtin University, Australia. Dr. Masoum is a senior member of IEEE. 